\title{
Microstructural Characterization of Hardened AISI 4140 Using TiN/SiC Coating
}

\author{
J. L. Bernal ${ }^{1}$, A. Irvin $^{1}$, E. Vera ${ }^{1}$, H. Abundis ${ }^{1}$, M. Villanueva ${ }^{1}$, A. García ${ }^{2}$, C.A. Lasorsa ${ }^{3}$, A. Medina ${ }^{4 a}$, \\ L. Béjar ${ }^{4 b}$, S. Borjas ${ }^{4 c}$ \\ 1. Automotive Mechanics Department, Universidad Politécnica de Pachuca, Hidalgo, México. \\ 2. Faculty of Science, Universidad Autónoma de San Luis Potosí, San Luis Potosí, México. \\ 3. Mechanics Department, Universidad Tecnológica Nacional, Haedo, Argentina. \\ ${ }^{4 a}$ Instituto de Investigaciones Metalúrgicas, ${ }^{4 b}$ Facultad de Ingeniería Mecánica, ${ }^{4 c}$ Instituto de Física y \\ Matemáticas, UMSNH, Michoacán, México.
}

In the PVD process it seeks to develop layers in order to provide both mechanical properties hardness combined as a contradictory ductility [1-3]. In particular the multilayers have been studied recently because it's many advantages. The architecture of these layers grown on steel substrates plays an important role since the construction of such coatings enables differentiation of each layer, e.g. composition, the present phases, morphology, thickness and layer sequence are determinants in the mechanical and tribological properties of the processed material [4-5]. In this research a characterization study of the multilayer deposition of $\mathrm{TiN} / \mathrm{SiC}$ coatings using physical vapor deposition technique PVD on a steel substrate it was performed.

The TiN coatings were produced in a BAI 1200 machine at Oerlikon Balzers in Mexico. They were deposited on 4140 alloy steel substrate with a high vacuum and at a temperature about $450{ }^{\circ} \mathrm{C}$ for 2 hours. Then, SiC coatings were deposited on TiN layer introducing the precursor hexamethyldisilazane (HMDS) $\mathrm{CH} 3 \mathrm{SSCH} 3$ and a process gas, which in our case was argon or methane in different processes within the plasma reactor, at variable pressures of $0.8 \mathrm{~atm}$. The ionization potential ranged from $700 \mathrm{~V}$ to $900 \mathrm{~V}$, and the substrate temperature was $500{ }^{\circ} \mathrm{C}$ for the methane process, and $600{ }^{\circ} \mathrm{C}$ for the argon process, for both processes were slightly different results. The rate of film growth is on average approx. $1 \mathrm{~mm} / \mathrm{h}$, and its average hardness is approx. $\sim 9$ on the Mohs scale.

The presence of SiC film on the surface of AISI 4140 steel was confirmed by Scanning Electron Microscopy (SEM), Energy Dispersive Spectroscopy (EDS) and X-Ray Diffraction (XRD) techniques. Figure 1 shows cross section images (SEM) of TiN and SiC film as well as EDS maps of Si, C, Ti and N on AISI 4140 steel, the XRD scans (Figure 2) confirmed the presence of a single SiC (PDF: ICSD 98 002 8310) and TiN (PDF: ICSD 98018 6008) phases formed in the AISI 4140 steel. The chemical composition of the sample surface is observed in Figure 3 and it is given in Table 1 confirming the presence of silicon carbide on its surface. These results demonstrate that the process of PVD applied to AISI 4140 steel formed superficial layers TiN/SiC.

\section{References:}

[1] Mats Larson, Michael Bromark, Per Hedenqvist,Sture Hogmark. Surface and Coatings Tecnology. 7677 (1995) 202-205.

[2] L.A. Dobrzanski, K. Lukaszkowicz. Archives of Materials Science and Engineering. 28 (2007) 549-556.

[3] S.A Naghibi, K. Raeissi, M.H. Fahti. Materials Chemistry and Physics. 148 (2014) 614-623.

[4] Y.P. Purandare, A.P. Ehiasarian, and P. Eh. Hovsepian. J. Vac. Sci Tecnol. 26 (2008) 288-296.

[5] E. Marin et al, Materials and Design. 89 (2016). 314-322. 

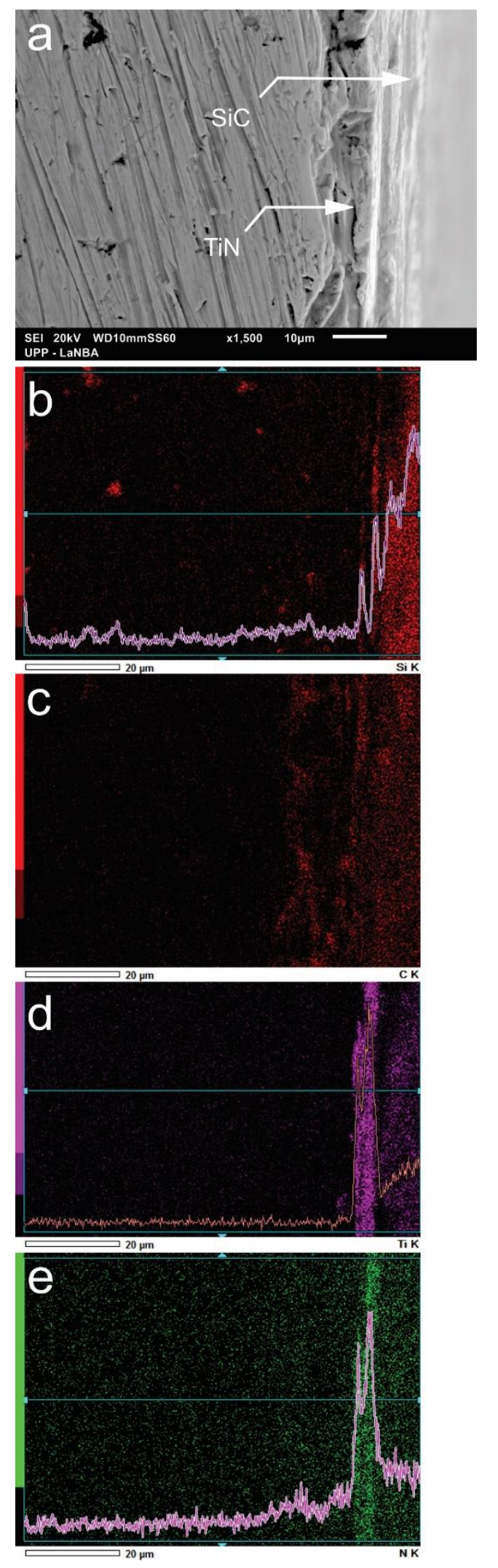

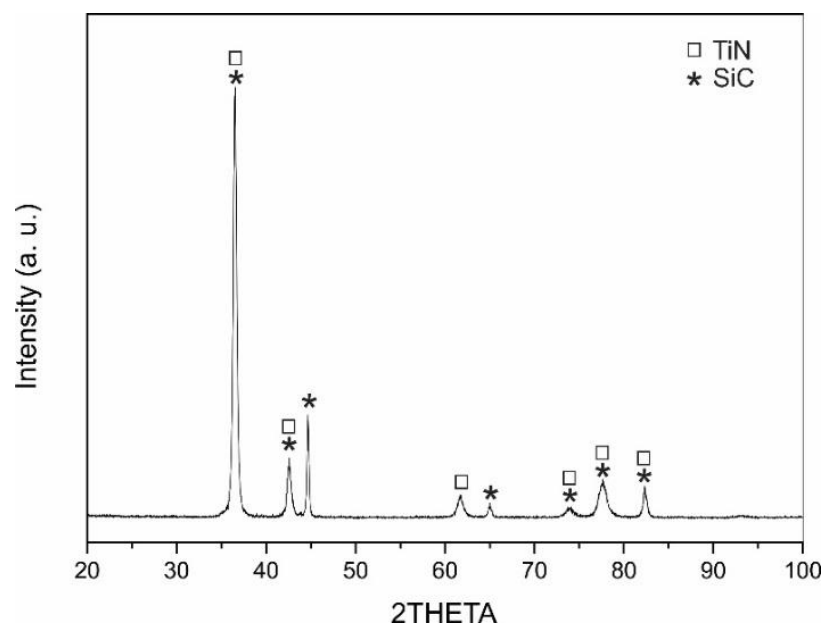

Figure 2.

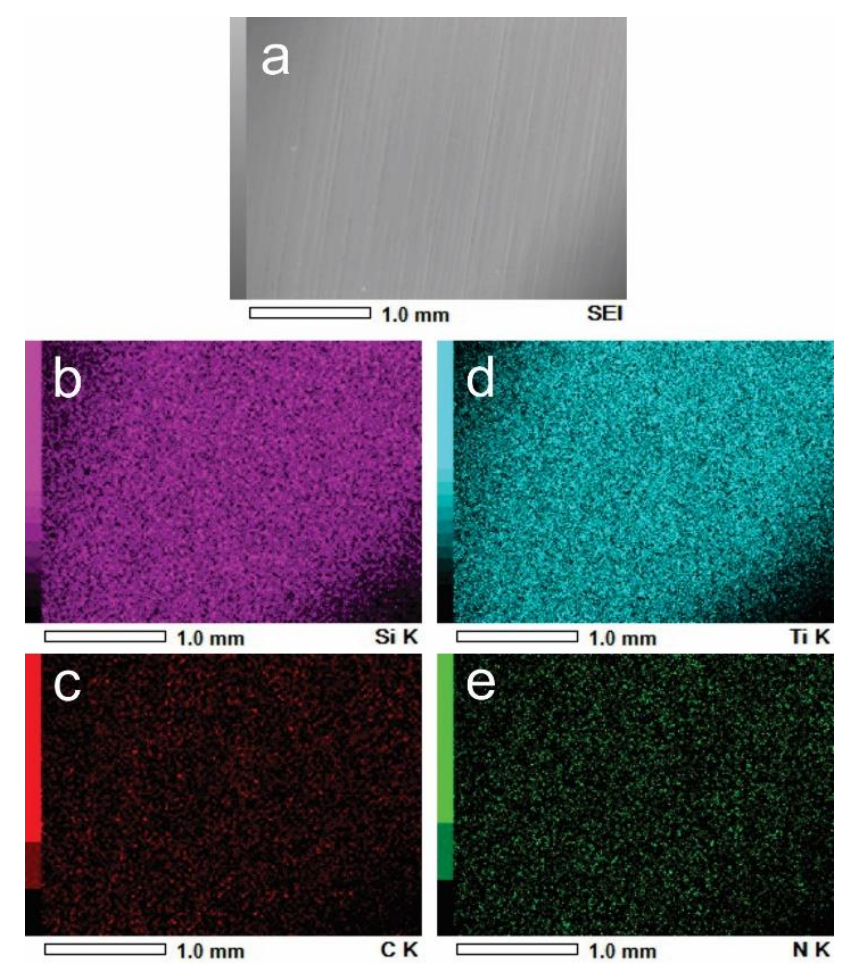

Figure 3.

Figure 2. XRD diffraction patterns of $\mathrm{SiC}$ and $\mathrm{TiN}$, and EDS maps (Fig. 3) of a) sample surface, b) Si, c) C, d) Ti and e) N.

\begin{tabular}{ccccc}
\hline Element & $\mathrm{C}$ & $\mathrm{N}$ & $\mathrm{Si}$ & $\mathrm{Ti}$ \\
\hline $\mathbf{W t} \%$ & 9 & 23.95 & 6.64 & 60.41 \\
\hline
\end{tabular}

Table 1. The chemical composition of sample surface [wt. \%]

Figure 1. SEM a) cross-sectional micrograph, b) Si, c) C, d) Ti, and e) $\mathrm{N}$ maps. 